\title{
Variants of Girls and Boys with Conduct Disorder: Anxiety Symptoms and Callous-Unemotional Traits
}

\author{
Felix Euler • Nils Jenkel • Christina Stadler • Klaus Schmeck • \\ Jörg M. Fegert • Michael Kölch • Marc Schmid
}

Published online: 28 October 2014

(C) Springer Science+Business Media New York 2014

\begin{abstract}
Recent research suggests that among the group of aggressive and antisocial adolescents, there are distinct variants who exhibit different levels of anxiety symptoms and callous-unemotional traits (CU traits). The purpose of the present study was to examine whether such variants are also present in male and female adolescents diagnosed with conduct disorder (CD). We used model-based cluster analysis to disaggregate data of 158 adolescents with CD (109 boys, 49 girls; mean age $=15.61$ years) living in child welfare and juvenile justice institutions. Three variants were identified: (1) CD only, (2) CD with moderate CU traits and anxiety symptoms, and (3) CD with severe CU traits. Variants differed in external validation measures assessing anger and irritability, externalizing behavior, traumatic experiences, and substance use. The $\mathrm{CD}$ variant with moderate $\mathrm{CU}$ traits and anxiety symptoms had the most severe pattern of psychopathology. Our results also indicated distinct profiles of personality development for all three variants. Gender-specific comparisons revealed differences between girls and boys with $\mathrm{CD}$ on clustering and external validation measures and a genderspecific cluster affiliation. The present results extend previously published findings on variants among aggressive and antisocial adolescents to male and female adolescents diagnosed with $\mathrm{CD}$.
\end{abstract}

Electronic supplementary material The online version of this article (doi:10.1007/s10802-014-9946-x) contains supplementary material, which is available to authorized users.

F. Euler $(\bowtie) \cdot$ N. Jenkel $\cdot$ C. Stadler $\cdot$ K. Schmeck $\cdot$ M. Schmid Department of Child and Adolescent Psychiatry, Psychiatric

University Clinics Basel, Wilhelm Klein-Strasse 27, 4012 Basel, Switzerland

e-mail: felix.euler@upkbs.ch

J. M. Fegert • M. Kölch

Department of Child and Adolescent Psychiatry and Psychotherapy,

University Hospital Ulm, Steinhoevelstrasse 5, 89075 Ulm,

Germany
Keywords Limited prosocial emotions · DSM-5 · Aggressive and antisocial behavior $\cdot$ Temperament and character .

Personality development $\cdot$ Cluster analysis

Conduct disorder (CD) is characterized by a pattern of violation of the basic rights of others, violation of age-appropriate norms or rules, and aggressive behavior towards peers, parents, teachers, and caregivers (American Psychiatric Association 2013). Children and adolescents with CD are a heterogeneous group characterized by distinct phenotypes, and several subtypes have been specified in previous investigations (Buitelaar et al. 2013; Hodgins et al. 2009; Stadler et al. 2010). One line of evidence has identified the presence of callous-unemotional traits ( $\mathrm{CU}$ traits) as an important subgroup characteristic. $\mathrm{CD}$ patients with $\mathrm{CU}$ traits show a particularly severe and stable pattern of aggressive behavior, benefit less from interventions, have distinct neurocognitive profiles, and specific etiological risk factors (Frick and Nigg 2012; Rowe et al. 2010; Moffitt et al. 2008). Because the presence of CU traits has repeatedly been shown to characterize a specific subgroup of children and adolescents with $C D$, the Diagnostic and Statistical Manual of Mental Disorders (5th ed.; DSM-5; American Psychiatric Association 2013) has added a CU specifier referred to as 'specifier for limited prosocial emotions' to the diagnostic criteria of $\mathrm{CD}$. The specifier designates those $\mathrm{CD}$ patients who can be described by a significant lack of remorse or guilt, callous lack of empathy, unconcern about their performance, and a shallow or deficient affect. Inclusion of the specifier to the DSM-5 diagnostic classification contributes markedly to differentiating the heterogeneous group of $\mathrm{CD}$ patients.

Another line of evidence with respect to subgroup differentiation has focused on the presence of comorbid anxiety symptoms. Hodgins et al. (2009) postulated that the presence of anxiety symptoms represents the main differentiation 
criterion within the group of individuals with persistent antisocial behavior. According to a meta-analysis by Angold et al. (1999), the risk for developing an anxiety disorder is three times higher in children with than in children without $\mathrm{CD}$. Moreover, epidemiological studies reported that the proportion of comorbid anxiety disorders in $\mathrm{CD}$ children ranges from 22 to $33 \%$ in the general population and from 60 to $75 \%$ in clinic-referred or institutionalized populations (Russo and Beidel 1994). However, it is still unclear if comorbid anxiety symptoms lead to more severe antisocial behavior or function as a protective factor. Earlier studies indicated that anxiety moderates the manifestation and severity of aggressive and antisocial behavior, while more recent studies concluded that the direction of the relationship differs depending on study group characteristics (Polier et al. 2012; Vloet and HerpertzDahlmann 2011). It has been proposed that in nonaggressive children, internalizing problems reduce the risk of future aggressive behavior while for aggressive children the risk of future aggressive behavior is increased (Olsson 2009; Sourander et al. 2007). In community and clinic-referred children and adolescents, severe conduct problems seem to be associated with increased internalizing problems, and comorbidity of conduct problems and internalizing problems is more frequent in clinical than in community samples (Polier et al. 2012). Gender-specific differences have also been reported, indicating that in girls with conduct problems the prevalence of comorbid anxiety is higher than in boys and is associated with more severe antisocial behavior (Lehto-Salo et al. 2009). In addition, specific anxiety constructs are related differently to the severity of conduct problems and CU traits (Olsson 2009). Frick and Ellis (1999) emphasized that it is important to differentiate between fear, possibly decreasing disruptive behavior, and anxiety as a negative affect that may be a result of the behavioral problems and subsequent stress. In a study with clinic-referred children, Frick et al. (1999) investigated the relationship of trait anxiety, conduct problems, and CU traits. Trait anxiety was positively correlated with conduct problems, and was uncorrelated or negatively correlated with $\mathrm{CU}$ traits. The authors concluded that trait anxiety in antisocial individuals might be a result of a higher rate of stressful life events that occur as a consequence of risk taking behavior. Moreover, the authors stated that the influence of CU traits might help to explain opposing findings regarding the relationship of anxiety symptoms and conduct problems. In summary, research on $\mathrm{CD}$ phenotypes indicates that both anxiety symptoms and CU traits are associated with a more severe pattern of conduct problems. In contrast to this, CU traits are negatively correlated with anxiety (Dolan and Rennie 2007; Frick et al. 1999; Pardini et al. 2007). Hence, the interrelation of CU traits, anxiety symptoms, and the severity of behavioral problems in CD patients seems to be complex and remains incompletely understood.

\section{Variants of Antisocial Youths: Merging CU Traits and Anxiety Symptoms}

Karpman $(1941,1948)$ introduced a distinction of psychopathy variants ${ }^{1}$ based on the presence or absence of anxiety, i.e., a primary and a secondary variant. According to this taxonomy, the two variants are phenotypically indistinguishable but differ with respect to the presence of anxiety and the motivational and etiological origins of antisocial and aggressive behavior. Recent studies applying model-based cluster analysis or latent-profile analysis in samples of adolescent offenders (Kimonis et al. 2011, 2012a, 2012b, 2013; Lee et al. 2010), clinic-referred (Kahn et al. 2013), and community samples of adolescents (Fanti et al. 2013), have identified similar variants based on levels of CU traits or psychopathic traits and anxiety symptoms. In a longitudinal study by Kimonis et al. (2011) with male adolescent offenders, subjects with the secondary variant reported more childhood abuse, depression, hostility, reactive aggression, psychosocial distress, and were more immature than subjects with the primary variant. A study investigating emotional processing in male adolescent offenders indicated that subjects with the secondary variant suffered more from distressing emotional stimuli, reported more maltreatment, anger problems and scored higher on negative emotionality compared to subjects with the primary variant and a comparison group (Kimonis et al. 2012a). In a similar investigation, Lee et al. (2010) also found clusters with altering levels of psychopathic traits and anxiety symptoms. Kimonis et al. (2012b) reported that incarcerated adolescents with the secondary variant had a higher frequency of substance abuse and were more likely to meet the diagnostic criteria for an alcohol or substance abuse disorder than those with the primary variant or offenders without psychopathic traits. In clinic-referred male and female adolescents, Kahn et al. (2013) found that individuals with elevated levels of CU traits, anxiety, and past trauma reported more physical and sexual abuse, scored higher on measures of impulsivity, behavioral inhibition, externalizing behavior, and aggression, than individuals with elevated CU traits and low levels of anxiety and trauma. Thus, recent interpretations of Karpman's taxonomy in samples of children and adolescents represent a promising approach to classify variants of antisocial youths based on the presence of $\mathrm{CU}$ traits and anxiety symptoms with distinct behavioral and psychosocial characteristics. Nonetheless, there are still several unresolved issues. First, most study populations in research investigating variants of aggressive and antisocial adolescents did not include subjects diagnosed with a psychiatric disorder according to the DSM. Hence, it is difficult to determine if similar variants are present in patients

\footnotetext{
${ }^{1}$ In line with Kimonis et al. (2011, 2012a) and Kahn et al. (2013), we use the term 'variants' instead of 'subtypes' since our aim was to identify prototypes instead of discrete categories of youths.
} 
diagnosed with $\mathrm{CD}$. Second, studies with aggressive and antisocial youths have focused on behavioral psychopathology associated with distinct variants. Based on earlier research reporting that $\mathrm{CD}$ is associated with a deviant pattern of personality development (Schmeck and Poustka 2001), we speculated that $\mathrm{CD}$ variants also show distinct profiles in personality dimensions. A widely used approach describing personality development is the psychobiological model by Cloninger et al. (1993). This conceptual model includes four temperament dimensions (i.e., novelty seeking, harm avoidance, reward dependence, and persistence) and three character dimensions (self-directedness, cooperativeness, and self-transcendence). The four temperament dimensions are conceptualized as early-developing biologically rooted behavioral tendencies that are relatively stable over time and situations and reflect the variability of behavioral and emotional responses in social interactions (Cloninger et al. 1991). The character dimensions indicate cognitive-intentional experienced attributes forming self-concepts, and describe differences in goals, values, and attitudes of an individual. Studies in CD patients showed that high novelty seeking and low harm avoidance are significantly correlated with externalizing behavior (Schmeck and Poustka 2001). Rettew et al. (2004) found that reward dependence and cooperativeness are lower in children with disruptive behavior disorders than in healthy controls or children with ADHD. In community children, harm avoidance was associated with internalizing problems, novelty seeking, self-transcendence, and reward dependence with externalizing problems (Copeland et al. 2004). To our knowledge, deviant personality development in different variants of antisocial adolescents has not previously been investigated. Third, the majority of studies that aimed to identify variants of aggressive and antisocial youths were conducted in male offenders. Although $\mathrm{CD}$ is more often diagnosed in boys than girls, the prevalence in girls is still between $1 \%$ and $3 \%$, and psychosocial development seems to be severely impaired. It has been argued that sex differences represent true differences in the sociocultural experiences and biogenetic development for boys and girls. Given that adolescent girls are at higher risk for anxiety and mood disorders, we can expect a higher amount of overlap among such disorders in CD girls. Previous research has confirmed that anxiety and depression symptoms, as well as substance abuse, are more common in CD girls than in CD boys (Keenan et al. 1999); Waschbusch (2002) showed that girls generally are less likely to develop $\mathrm{CD}$, but those who do, are more likely to show comorbid ADHD symptoms, leading to more severe psychopathology overall. Consequently, a gender paradox for adolescents with CD has been discussed (Keenan et al. 2010; Pajer et al. 2008; Stadler et al. 2013). That is, the gender with the lower prevalence for $\mathrm{CD}$ appears more at risk to show a comorbid disorder than the gender with the higher prevalence of the disorder. If the gender paradox also applies for CU traits, one would expect $\mathrm{CD}$ girls to generally show lower levels of $\mathrm{CU}$ traits, but in presence of $\mathrm{CU}$ traits, to elicit a more severe pattern of behavioral problems and comorbid psychopathology. To our knowledge, only three studies have investigated the interrelation of CU traits, the presence of comorbid psychopathology, and the severity of aggressive and antisocial behavior in mixed gender populations (Fanti et al. 2013; Kahn et al. 2013) or in girls only (Pardini et al. 2012). Compared to boys, girls generally score lower on CU traits, show less severe antisocial behavior, are less often diagnosed with $\mathrm{CD}$, and score higher on internalizing problems (Frick and Nigg 2012; Stadler et al. 2013). In a study attempting to distinguish between primary and secondary variants of psychopathy in a community sample of male and female adolescents, Fanti et al. (2013) found that there were more boys than girls in both variants. However, girls and boys exhibited similar phenotypic manifestations within identified variants. Overall, studies investigating gender-specific variants of $\mathrm{CD}$ are still scarce, and it remains unclear if a gender-specific affiliation to previously identified variants can be assumed for $\mathrm{CD}$ patients.

\section{Aim of the Present Study}

Given the limitations of previous investigations, we aimed to answer the following research questions: (a) Are variants of antisocial youths with different levels of anxiety symptoms and $\mathrm{CU}$ traits described in previous investigations with adolescent offenders, clinic-referred, and community samples of youths also present in adolescents diagnosed with CD? (b) Do identified clusters of $\mathrm{CD}$ patients differ significantly with respect to behavioral characteristics, measures of psychopathology, and personality development that have previously been associated with aggressive and antisocial behavior in children and adolescents? (c) Do CD girls and boys differ on variables relevant for identification and description of variants, namely CU traits, anxiety symptoms, externalizing behavior, traumatic experiences, substance abuse, and personality development, and is there a gender-specific pattern of cluster affiliation?

To answer our first study question, we applied model-based cluster analysis to disaggregate $\mathrm{CD}$ variants, based on anxiety symptoms and $\mathrm{CU}$ traits. We expected to find $\mathrm{CD}$ variants with and without $\mathrm{CU}$ traits and hypothesized that $\mathrm{CD}$ patients with $\mathrm{CU}$ traits are further distinguishable based on the presence or absence of anxiety symptoms. For the second study question, we compared emerging clusters with respect to levels of anger and irritability, externalizing behavior, traumatic experiences, substance abuse, and personality development. We hypothesized that the combination of $\mathrm{CU}$ traits and anxiety symptoms in CD patients would be associated with more severe comorbid psychopathology. Further, we expected that in $\mathrm{CD}$ patients with elevated $\mathrm{CU}$ traits, personality 
development in the temperament dimension 'novelty seeking', and the character dimension 'cooperativeness' would be deviant. We additionally hypothesized that $\mathrm{CD}$ patients with a combination of $\mathrm{CU}$ traits and anxiety symptoms would show deviant development in the temperament dimension 'harm avoidance' and the character dimension 'self-directedness'. To answer our third study question we initially compared CD girls and boys, irrespective of cluster affiliation, on clustering and external validation measures and subsequently analyzed gender distribution in emerging clusters. In line with previous investigations, we hypothesized that $\mathrm{CD}$ girls would show higher levels of anxiety symptoms and lower levels of $\mathrm{CU}$ traits than CD boys. We expected CD girls to be overrepresented in the variant with anxiety symptoms and CU traits, and underrepresented in the variant with severe CU traits.

\section{Method}

\section{Participants}

The study sample was taken from the Swiss Model Project for Clarification and Goal-attainment in Child Welfare and Juvenile-Justice Institutions (MAZ; for details of the study see Schmid et al. 2013). Between 2007 and 2011, 592 adolescents living in 64 different socio-educational institutions in the German-, French-, and Italian-speaking parts of Switzerland participated in the survey. All institutions were accredited by the Swiss Ministry of Justice. Adolescents were admitted either by criminal law, civil law, or by voluntary placement. Voluntary or hospitalisation by civil law occurred if adolescents were no longer able to live in their family or environment of origin due to severe psychological or behavioral problems, or precarious life conditions. Adolescents' return to their family or environment of origin was arranged if circumstances were evaluated as safe and acceptable. In case of hospitalisation by penal law adolescents were to be released upon completion of their sentence. To participate, adolescents had to have been placed for at least 1 month in the institution, prior to the conduct of the survey. To address the present research questions, we selected participants between the ages of 12 and 18 years that had been diagnosed with $C D$ as the primary axis I diagnosis according to DSM-IV-TR (American Psychiatric Association 2000) and complete datasets on the clustering variables from the total MAZ sample. Exclusion criteria were low intelligence scores (IQ $<70$ ), assessed with the Culture Fair Intelligence Test (Weiss 2006) or the Raven Progressive Matrices (Raven et al. 2003), and comorbid psychotic disorders. This yielded a subsample of 158 participants (109 boys, 49 girls)) for the present study. The mean age of the final sample was $15.61(\mathrm{SD}=1.49)$ and the mean IQ was 95.79 (SD 13.14). Of the 158 adolescents $39 \%(N=62)$ had CD without comorbid disorders and $61 \%(N=96)$ had one or more comorbid disorders. The most frequent comorbid disorder was ADHD $(35 \%, N=56)$, followed by substance related disorders $(23 \%, N=36)$, anxiety disorders $(20 \%, N=32)$ and mood disorders $(12 \%, \mathrm{~N}=19)$. Demographic characteristics and psychometric data were obtained from the MAZ data files.

\section{Procedure}

In a first step, child welfare and juvenile-justice institutions in Switzerland were contacted by the MAZ study team. After institutions agreed to participate, social workers were introduced to the survey. During counseling appointments, adolescents and the person entitled to their custody were informed about the project. If written informed consent for the survey was given, participants and qualified caseworkers underwent the Kiddie Schedule for Affective Disorders and Schizophrenia-Present and Lifetime Version (Delmo et al. 2005) with trained professionals visiting the institution. Diagnostic information was integrated across informants after completion of the structured clinical interviews. Subsequently, computeradministered questionnaires were completed. For the otherreport assessments, caseworkers that had been assigned as primary caretaker for the participating adolescent during and after the time in the institution were selected. The selected caseworkers had to know the adolescent for at least 1 month and additionally had to confirm that they knew the adolescent well enough and felt comfortable to validly answer the survey questions. Information disclosed by the youths remained confidential and feedback was made available to the caseworker only if the adolescent consented. Ethical approval for the study was obtained by the Institutional Review Board of the University of Basel, Switzerland.

\section{Measures}

CU Traits To assess CU traits, we used the 'callous, unemotional' (CU) dimension of the Youth Psychopathic Traits Inventory (YPI; Andershed et al. 2002), a self-report measure for adolescents. The YPI CU dimension includes 20 items and comprises the subscales 'callousness','unemotionality', and'remorselessness'. Participants rate how much each item applies to them on a 4-point Likert scale $(1=$ 'does not apply at all', $2=$ 'does not apply well', $3=$ 'applies fairly well', $4=$ 'applies very well'). We administered a German version of the YPI. The original YPI was translated and back-translated by two bilingual mother-tongue speakers. Discrepancies were discussed and corrected with the original author. The German version of YPI was validated in a large German-speaking school sample $(N=840)$ in Switzerland. Internal consistency and the three-factor structure were confirmed (Stadlin et al., Construct Validity and factor structure of the German Version of the Youth Psychopathic Traits Inventory (YPI) in a representative school sample, submitted). Means, SD, and internal 
consistencies for the YPI CU dimension of the Swiss norm population are reported in the supplementary material (S1). For the current sample, the YPI CU dimension demonstrated good internal consistency $(\alpha=0.80)$.

Anxiety Symptoms, Anger, Traumatic Experiences and Substance Abuse We applied the Massachusetts Youth Screening Instrument Second Version (MAYSI-2; Grisso and Barnum 2006) to screen for anxiety symptoms, anger, traumatic experiences and substance abuse. The MAYSI-2 is a self-report screening tool developed to identify youths with mental health needs in juvenile-justice institutions. A number of investigations indicate adequate psychometric properties and internal consistency for the MAYSI-2 (for a review see Grisso et al. 2012). The questionnaire consists of 52 questions answered with 'yes' or 'no'. The instrument contains seven scales: 'alcohol/drug use' (ADU), 'angry-irritable' (AI), 'depressed-anxious' (DA), 'somatic complaints' (SC), 'suicide ideation' (SI), 'thought disturbance' (TD), and 'traumatic experiences' (TE). For all scales except the TE scale, caution and warning cutoff points are available. We used the DA scale to assess symptoms of anxiety. The DA scale contains nine items assessing depressed and/or anxious feelings. The MAYSI-2 AI scale was used to measure feelings of preoccupying anger. The scale captures a general tendency of anger-related irritability, frustration, and stress. To assess traumatic life events we used the MAYSI-2 TE scale. The TE scale measures self-reported experience of potential traumatizing live events. The MAYSI-2 ADU scale was applied to capture frequency and pervasiveness of substance use. The MAYSI- 2 DA $(\alpha=0.75)$, AI $(\alpha=0.80)$ and ADU $(\alpha=0.88)$ scales showed good, the TE scale $(\alpha=$ 0.62 ) sufficient internal consistencies in the present study.

Externalizing Behavior To assess externalizing behavior via other-report, qualified caseworkers completed the Child Behavior Checklist/4-18 (CBCL, Achenbach 1991). We used the 'aggressive behavior' (AB), the'delinquent behavior' (DB), and the 'attention problems' (AP) syndrome scales of the CBCL. The AB $(\alpha=0.83)$, the $\mathrm{DA}(\alpha=0.80)$, and the AP $(\alpha=0.70)$ CBCL scales showed good internal consistencies.

Temperament and Character We applied the Junior Temperament and Character Inventory-Revised (JTCI 12-18 R; Goth and Schmeck 2009), a self-report measure to assess personality development. In line with Cloninger's biopsychosocial model of personality, the JTCI 12-18 R assesses four temperament scales ('novelty seeking', 'harm avoidance', 'reward dependence', 'persistence') and three character scales ('selfdirectedness', 'cooperativeness', 'self-transcendence'). The questionnaire contains 103 items. For the German JTCI 1218 , good scale reliabilities (alphas between 0.79 and 0.85 ) and excellent construct validity have been shown (Schmeck et al. 2001). We used the temperament dimensions 'novelty seeking'
(NS), and 'harm avoidance' (HA) and the character dimension 'self-directedness' (SD), and 'cooperativeness' (CO). Internal consistencies for the JTCI dimensions NS $(\alpha=0.79)$, HA ( $\alpha=$ $0.80), \mathrm{CO}(\alpha=0.85)$, and $\mathrm{SD}(\alpha=0.83)$ in the present study were good. For the interpretation of the JTCI 12-18 R temperament and character dimensions, cutoff scores from a norm population are available (Goth and Schmeck 2009).

\section{Statistical Analyses}

To address the primary study aim to identify variants of adolescents with $\mathrm{CD}$, we performed the TwoStep cluster analysis (CA) procedure using IBM-SPSS software package, Version 19 (IBM SPSS Inc., Chicago, USA). This procedure is a scalable CA algorithm developed to automatically find the optimal number of clusters in large datasets. In a first step, the procedure calculates the Bayesian information criterion (BIC) for each number of clusters in a given range. In a second step, a model-based hierarchical technique refines the initial number by estimating the ratio of distance between clusters. We used the YPI CU dimension and the MAYSI-2 AD scale as clustering variables. We interpreted means of each cluster on the MAYSI-2 AD scale according to published cutoff points (MAYSI-2; Grisso and Barnum 2006). Because no established cutoff scores are available for the YPI, we compared scores on the YPI CU for each cluster with an age-matched Swiss school sample ( $N=840$; 480 boys, 360 girls) using independent samples $t$-test. In line with Cauffman et al. (2009), we additionally interpreted mean scores of identified clusters that were at least one SD above the mean of the YPI norm sample as elevated. Because of the high prevalence of comorbid disorders in the sample, we used chi-square analysis to test if identified clusters differed according to the presence of comorbid disorders. Results are available in the supplementary material (S2). We used univariate analyses of variance (ANOVAs) to compare resulting clusters on clustering measures, and for post-hoc multiple comparisons between clusters we applied the Tukey HSD test. To compare identified clusters on theoretical, empirical, and clinically relevant dimensions we conducted univariate ANOVAs. We used the Tukey HSD test for multiple comparisons between clusters. We additionally performed bivariate analysis for age, gender and attention problems with all clustering and external validation measures. Results are reported in the supplementary material (S3). If bivariate analysis indicated significant correlations of age, gender, or attention problems with a clustering or an external validation measure, these variables were included as covariates in univariate analysis of covariance (ANOCVAs) for cluster comparisons on that measure. Because results of group comparisons remained unchanged after inclusion of the covariates, we only report ANOVA results. For the genderspecific analysis, we used independent samples t-tests to compare $\mathrm{CD}$ girls and boys on clustering and external 
validation measures irrespective of cluster affiliation. Levene's test confirmed homogeneity of variance for all whole-group gender comparisons, with the exception for the MAYIS-2 AI and JTCI 12-18 R CO dimensions. Reported results for these dimensions are adjusted for inequality of variances. We used chi-square analysis to test gender distribution in identified clusters.

\section{Results}

\section{Cluster Analysis}

The two-step cluster procedure indicated a three-cluster solution (Cluster I, $N=77$; Cluster II, $N=31$; Cluster III, $N=50$ ). The algorithm judged the three-cluster solution to be the best fit for our data, with a BIC change of -19.94 between the twoand three-cluster solutions and a ratio of distance measure of 1.81. The three-cluster solution represented a better fit than the four-cluster solution with a BIC change between the threeand four-cluster solution of -1.92 and a ratio of distance measure of 1.53. The correlation between the MAYSI-2 DA scale and YPI CU dimension was low (CU: $r=0.14, p=0.09$ ). There were no significant differences between clusters on age or IQ. Clusters differed significantly on the MAYSI-2 DA scale $\left(\mathrm{F}(2,155)=131.98, p<0.001 ; \eta^{2}=0.63\right)$ and the YPI CU dimension $\left(\mathrm{F}(2,155)=99.85, p<0.001 ; \eta^{2}=0.56\right)$. Post-hoc comparisons revealed significant differences for all betweencluster comparisons on the MAYSI-2 DA scale and the YPI $\mathrm{CU}$ dimension. Table 1 shows the mean scores for clustering and external validation measures for the total study sample and each CD variant, and lists results of post-hoc group comparisons. On the MAYSI-2 DA scale Cluster II had a mean score in the warning range, while Cluster I and III had a mean score in the normal range. For the YPI CU dimension, independent samples t-tests revealed that Cluster II ( $\mathrm{t}(869)$ $=2.92, p<0.01)$ and Cluster III $(\mathrm{t}(888)=12.61, p<0.001) \mathrm{had}$ significant higher scores than the Swiss High School norm sample. Cluster I did not differ from the Swiss High-School sample. Cluster III had a mean score more than 1 SD above the mean of the High School sample. According to the psychometric profile on the clustering variables, Cluster I designated a 'CD only variant' ( $\mathrm{CD}$ only), Cluster II a ' $\mathrm{CD}$ variant with moderate $\mathrm{CU}$ traits and anxiety symptoms' (CD $\mathrm{CU}^{+} \mathrm{ANX}^{+}$), and Cluster III a ' $\mathrm{CD}$ variant with severe $\mathrm{CU}$ traits' $\left(\mathrm{CD} \mathrm{CU}^{++}\right)$. These labels are further used to refer to the respective clusters in this manuscript.

Validating and Comparing Identified Variants

On the MAYSI-2 AI scale, variants differed significantly ( $F$ $\left.(2,155)=33.68, p<0.001 ; \eta^{2}=0.30\right)$ and post-hoc tests confirmed that all between-variants comparisons were significant. The score of the $\mathrm{CD} \mathrm{CU}^{+} \mathrm{ANX}^{+}$variant on this scale was in the warning range, the score of the $\mathrm{CD} \mathrm{CU}^{++}$variant was in the caution range and the score of the $C D$ only variant was in the normal range. Figure 1 shows the z-scores on clustering and external validation measures for identified variants. To analyze if variants differed on self-reported traumatic experiences, we compared scores on the MAYSI-2 TE scale. ANOVA results indicated significant differences between variants $\left(F(2,155)=15.41, p<0.001 ; \eta^{2}=0.17\right)$. Post-hoc tests confirmed significant differences between the $\mathrm{CD} \mathrm{CU}^{+} \mathrm{ANX}^{+}$ variant and the two other variants. The $\mathrm{CD} \mathrm{CU}^{+} \mathrm{ANX}^{+}$variant scored in the caution range of the MAYSI-2 TE. The two other clusters had scores in the normal range. We used the MAYSI-2 ADU scale to analyze self-reported past substance use. ANOVA results revealed a significant difference $(F(2,155)$ $\left.=8.52, p<0.001 ; \eta^{2}=0.10\right)$ between variants. Post-hoc comparisons showed significant differences between the $C D$ $\mathrm{CU}^{+} \mathrm{ANX}^{+}$, and the $\mathrm{CD}$ only variant. The $\mathrm{CD} \mathrm{CU}^{+} \mathrm{ANX}^{+}$ and the $\mathrm{CD} \mathrm{CU}^{++}$variant had a mean score in the caution range, while the mean score for the $\mathrm{CD}$ only variant was in the normal range.

On the $\mathrm{CBCL} \mathrm{AB}$ and the $\mathrm{DB}$ syndrome scales, the $\mathrm{CD} \mathrm{CU}^{+} \mathrm{ANX}^{+}$variant had a $\mathrm{T}$-score in the clinical range (T-score $\geq 70$ ), while the $\mathrm{CD}$ only and the $\mathrm{CD} \mathrm{CU^{++ }}$ variants scored in the borderline clinical range (T-score $\geq 65$ ). On the CBCL AP syndrome scale the $\mathrm{CD} \mathrm{CU}^{+} \mathrm{ANX}^{+}$ variant had a $\mathrm{T}$-score in the borderline clinical range (T-score $\geq 65$ ), the two other variants scored in the normal range. Variants differed significantly on the CBCL $\mathrm{AB}$ $\left(F(2,151)=3.45, p=0.034 ; \eta^{2}=0.04\right.$, DB $(F(2,151)=7.61$, $\left.p<0.01 ; \eta^{2}=0.09\right)$, and $\mathrm{AP}\left(F(2,151)=3.31, p=0.034 ; \eta^{2}=\right.$ $0.04)$ syndrome scales. Post-hoc tests showed that the $C D$ $\mathrm{CU}^{+} \mathrm{ANX}^{+}$variant had significantly higher scores than the $\mathrm{CD}$ only variant on the $\mathrm{CBCL} \mathrm{AB}$ and the $\mathrm{DB}$ syndrome scales. Compared to the $\mathrm{CD} \mathrm{CU}^{++}$variant, the $\mathrm{CD} \mathrm{CU}^{+} \mathrm{ANX}^{+}$ variant scored significantly higher on the CBCL DB and the AP syndrome scales.

Last, we tested if variants differed on the JTCI temperament scales NS and HA as well as the JTCI character scales $\mathrm{SD}$ and $\mathrm{CO}$. In line with our hypothesis, results showed significant differences between variants in both temperament dimensions [NS: $(F(2,155)=8.60, p<0.001) ; \eta^{2}=0.10$; HA: $\left.\left(F(2,155)=10.04, p<0.001 ; \eta^{2}=0.23\right)\right]$. The $\mathrm{CD} \mathrm{CU}^{+} \mathrm{ANX}^{+}$ and the $\mathrm{CD} \mathrm{CU}^{++}$variants had higher T-scores in the NS dimension than the $\mathrm{CD}$ only variant, and post-hoc comparisons confirmed significant differences between the $\mathrm{CD}$ only variant and both other variants. In the HA dimension, post-hoc comparisons indicated that the $\mathrm{CD} \mathrm{CU}^{+} \mathrm{ANX}^{+}$variant scored significantly higher than the other two variants. CD Variants also differed significantly on both character dimensions [SD: $\left(F(2,155)=13.08, p<0.001 ; \eta^{2}=0.14\right) ; \mathrm{CO}:(F(2,155)=$ $\left.\left.19.79, p<0.001 ; \eta^{2}=0.20\right)\right]$ and post-hoc comparisons 
Table 1 Mean scores for clustering and external validation measures and results of group comparisons for identified variants

\begin{tabular}{|c|c|c|c|c|c|c|c|c|c|c|c|}
\hline & \multicolumn{2}{|c|}{$\begin{array}{l}\text { total sample } \\
(n=158)\end{array}$} & \multicolumn{2}{|c|}{$\begin{array}{l}\text { CD only } \\
(n=77)\end{array}$} & \multicolumn{2}{|c|}{$\begin{array}{l}\mathrm{CD} \mathrm{CU}^{+} \mathrm{ANX}^{+} \\
(n=31)\end{array}$} & \multicolumn{2}{|c|}{$\begin{array}{l}\mathrm{CD} \mathrm{CU}^{++} \\
(n=50)\end{array}$} & \multirow{2}{*}{$\begin{array}{l}\text { CD only vs. } \\
\mathrm{CD} \mathrm{CU}^{+} \mathrm{ANX}^{+} \\
p\end{array}$} & \multirow{2}{*}{$\begin{array}{l}\text { CD only vs. } \\
\mathrm{CD} \mathrm{CU}^{++} \\
p\end{array}$} & \multirow{2}{*}{$\begin{array}{l}\text { CD only vs. } \\
\mathrm{CD} \mathrm{CU}^{++} \\
p\end{array}$} \\
\hline & M & (SD) & M & (SD) & M & (SD) & M & (SD) & & & \\
\hline \multicolumn{12}{|l|}{$Y P I$} \\
\hline callous unemotional & 11.36 & $(2.51)$ & 9.75 & $(1.48)$ & 11.07 & $(1.74)$ & 14.03 & $(1.89)$ & $<0.01$ & $<0.001$ & $<0.001$ \\
\hline \multicolumn{12}{|l|}{ MAYSI-2 } \\
\hline depressed-anxious & 2.99 & $(2.35)$ & 1.62 & $(1.41)$ & $6.58^{1}$ & $(1.31)$ & 2.86 & $(1.54)$ & $<0.001$ & $<0.001$ & $<0.001$ \\
\hline angry-irritable & 5.13 & $(2.71)$ & 3.79 & $(2.48)$ & $7.68^{2}$ & $(1.30)$ & $5.60^{2}$ & $(2.41)$ & $<0.001$ & $<0.001$ & $<0.001$ \\
\hline Traumatic experiences & 2.57 & $(1.47)$ & 2.16 & $(1.44)$ & $3.74^{2}$ & $(1.00)$ & 2.48 & $(1.39)$ & $<0.001$ & $\mathrm{~ns}$ & $<0.001$ \\
\hline alcohol/ drug use & 5.13 & $(2.71)$ & 2.87 & $(2.70)$ & $5.23^{2}$ & $(2.85)$ & $4.04^{2}$ & $(2.84)$ & $<0.001$ & $\mathrm{~ns}$ & ns \\
\hline \multicolumn{12}{|l|}{$C B C L$} \\
\hline aggressive behavior & 68.00 & $(10.75)$ & $66.20^{3}$ & (10.89) & $72.20^{4}$ & $(9.64)$ & $68.16^{3}$ & $(10.67)$ & $=0.026$ & ns & ns \\
\hline delinquent behavior & 67.71 & $(8.44)$ & $65.44^{3}$ & (8.69) & $73.00^{4}$ & $(8.01)$ & $67.94^{3}$ & $(6.79)$ & $<0.001$ & $\mathrm{~ns}$ & $=0.019$ \\
\hline attention problems & 64.95 & $(8.00)$ & 64.37 & $(7.81)$ & $68.23^{3}$ & $(8.36)$ & 63.81 & $(7.68)$ & ns & ns & $=0.044$ \\
\hline \multicolumn{12}{|l|}{ JTCI } \\
\hline novelty seeking & 54.56 & $(9.88)$ & 51.36 & (10.34) & 57.61 & $(7.72)$ & 57.58 & $(8.90)$ & $<0.01$ & $<0.01$ & ns \\
\hline harm avoidance & 49.27 & $(9.62)$ & 47.36 & $(9.24)$ & 55.81 & $(7.46)$ & 48.16 & $(9.79)$ & $<0.001$ & ns & $<0.01$ \\
\hline self-directedness & 47.37 & $(10.53)$ & 51.26 & (10.18) & 41.52 & $(9.61)$ & 45.02 & $(9.32)$ & $<0.001$ & $<0.01$ & ns \\
\hline cooperativeness & 46.20 & (11.01) & 50.23 & $(9.70)$ & 47.71 & $(8.10)$ & $39.06^{5}$ & (10.74) & $\mathrm{ns}$ & $<0.001$ & $<0.01$ \\
\hline
\end{tabular}

$p$ values refer to post hoc comparisons based on Tukey HSD tests for identified variants. $C D$ only $\mathrm{CD}$ only variant; $C D C U^{+} A N X^{+} \mathrm{CD}$ variant with moderate. CU traits and anxiety symptoms; $C D C U^{++} \mathrm{CD}$ variant with severe $\mathrm{CU}$ traits, $Y P I$ Youth Psychopathic Traits Inventory, mean scores, $C B C L$ Child Behavior Checklist, T-scores; MAYSI-2Massachusetts Youth Screening Instrument-Second Version, raw scores; JTCIJunior Temperament and Character Inventory-Revised, T-scores. ${ }^{1}$ MAYSI-2 scores in the warning range; ${ }^{2}$ MAYSI-2 scores in the caution range; ${ }^{3}$ CBCL T-score above cutoff for borderline clinical relevance (T-score $\geq 65$ ); ${ }^{4} \mathrm{CBCL}$ T-score above cutoff for clinical relevance (T-score $\geq 70$ ); ${ }^{5} \mathrm{JTCI}$ T-score below average of norm population (T-score $<40)$

indicated that in the SD dimension the CD only variant scored significantly higher than both other variants. In the CO dimension, significant differences between all variants in posthoc comparisons were present. Compared to the norm population, the $\mathrm{CD} \mathrm{CU}^{++}$variant obtained a T-score below average $(\mathrm{T} \leq 40)$ in the CO dimension the. Scores on all the other JTCI dimensions for each of the $\mathrm{CD}$ variants were in the normal range.

\section{Gender-Specific Analysis}

To investigate gender-specific issues, we first compared scores of $\mathrm{CD}$ girls and boys on clustering and external validation measures, irrespective of cluster affiliation. Figure 2 indicates mean z-scores on clustering and external validation measures for $\mathrm{CD}$ girls and $\mathrm{CD}$ boys. Results of the independent samples $t$-test indicated that CD girls scored significantly higher on the MAYSI-2 DA $(t(156)=-4.47, p<0.001)$, ADU $(t(156)=-3.12, p=0.046)$, $\mathrm{AI}(t(156)=-3.12, p<0.01)$ and the $\mathrm{CBCL} \mathrm{DB}(t(152)=5.38$, $p<0.001)$, and AP $(t(152)=2.40, p=0.018)$ scales. Girls had also significantly higher scores in the JTCI 12-18 R CO $(t(156)=-2.09, p=0.038)$ and HA $(t(156)=-4.40, p<0.001)$ dimensions. Boys achieved higher values on the YPI CU $(t(156)=4.04, p<0.001)$ and JTCI 12-18 R SD $(t(156)=2.13$, $p=0.034)$ dimensions. No significant gender differences were present on the MAYSI-2 TE, CBCL AB, and the JTCI 12-18 R NS scales.

Subsequently, we tested if gender distribution differed between variants. Of the $49 \mathrm{CD}$ girls, $51.0 \%(N=25)$ were in the $\mathrm{CD}$ only, $36.7 \%(N=18)$ in the $\mathrm{CD} \mathrm{CU}^{+} \mathrm{ANX}^{+}$, and $12.2 \%$ $(N=6)$ in the $\mathrm{CU}^{++}$variant. Of the $109 \mathrm{CD}$ boys, $47.7 \%(N=$ $52)$ were in the $\mathrm{CD}$ only, $11.9 \%(N=13)$ in the $\mathrm{CD}$ $\mathrm{CU}^{+} \mathrm{ANX}^{+}$, and $40.4 \%(N=44)$ in the $\mathrm{CU}^{++}$variant. Gender distribution between clusters differed significantly $\left(\chi^{2}=\right.$ $19.13, \mathrm{~N}=158, p<0.001)$. As expected, girls were overrepresented in the $\mathrm{CD} \mathrm{CU}^{+} \mathrm{ANX}^{+}$variant.

\section{Discussion}

The current study aimed to distinguish between variants of adolescents with $\mathrm{CD}$ based on the presence of $\mathrm{CU}$ traits and 
Fig. 1 Mean z-scores on clustering and external validation measures for identified variants. Subscripts $(\mathbf{a}, \mathbf{b}, \mathbf{c})$ denote significant differences between variants in post-hoc tests $(p<0.05)$. Order of the letters indicates severity of psychopathology. $C D$ only $=\mathrm{CD}$ only variant; $C D C U^{+} A N X^{+}=\mathrm{CD}$ variant with moderate $\mathrm{CU}$ traits and anxiety symptoms; $C D$ $C U^{++}=\mathrm{CD}$ variant with severe $\mathrm{CU}$ traits; $Y P I=$ Youth Psychopathic Traits Inventory; MAYSI$2=$ Massachusetts Youth Screening Instrument-Second Version; $C B C L=$ Child Behavior Checklist 4/18; JTCI=Junior Temperament and Character Inventory-Revised

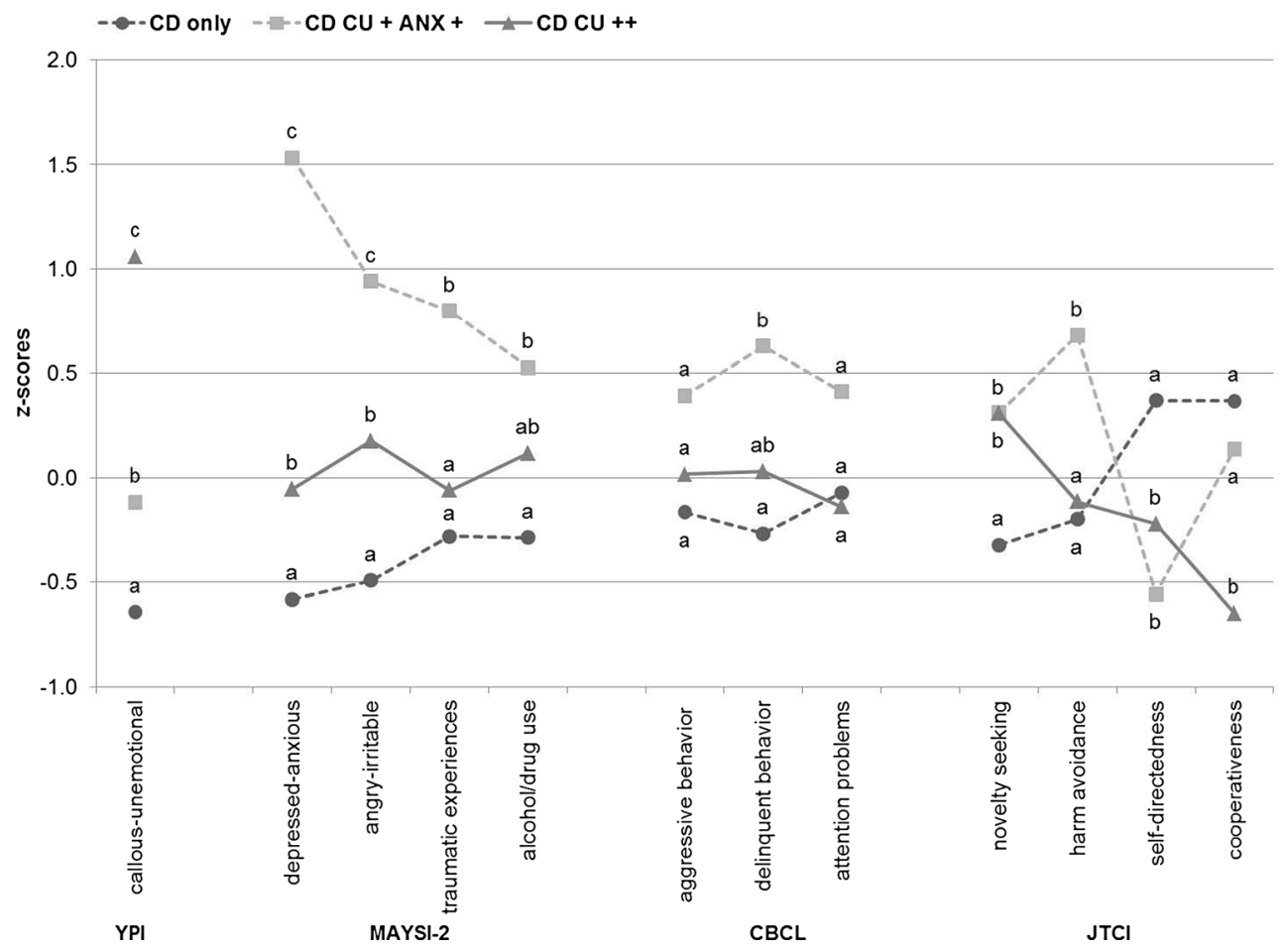

anxiety symptoms in adolescents living in child-welfare and juvenile-justice institutions. We identified three CD variants with distinct patterns of psychopathology and variable deviations of personality development. The CD variant with moderate CU traits and elevated anxiety symptoms showed the most severe psychopathology. Irrespective of cluster affiliation, gender-specific analysis revealed that $\mathrm{CD}$ girls had more severe behavioral problems while CD boys had higher levels of CU traits. Consequently, the proportion of girls and boys in identified variants differed substantially.

Before further interpreting our results, we outline several limitations of the present study. First, we quantified the extent
Fig. 2 Mean z-scores on clustering and external validation measures for CD girls and CD boys. Asterisks indicate significant differences in independent samples t-tests: $* * * p<0.001, * * p<0.01$, ${ }^{*} p<0.05$. YPI=Youth Psychopathic Traits Inventory; MAYSI2=Massachusetts Youth Screening Instrument-Second Version; $C B C L=$ Child Behavior Checklist 4/18; JTCI=Junior Temperament and Character Inventory-Revised

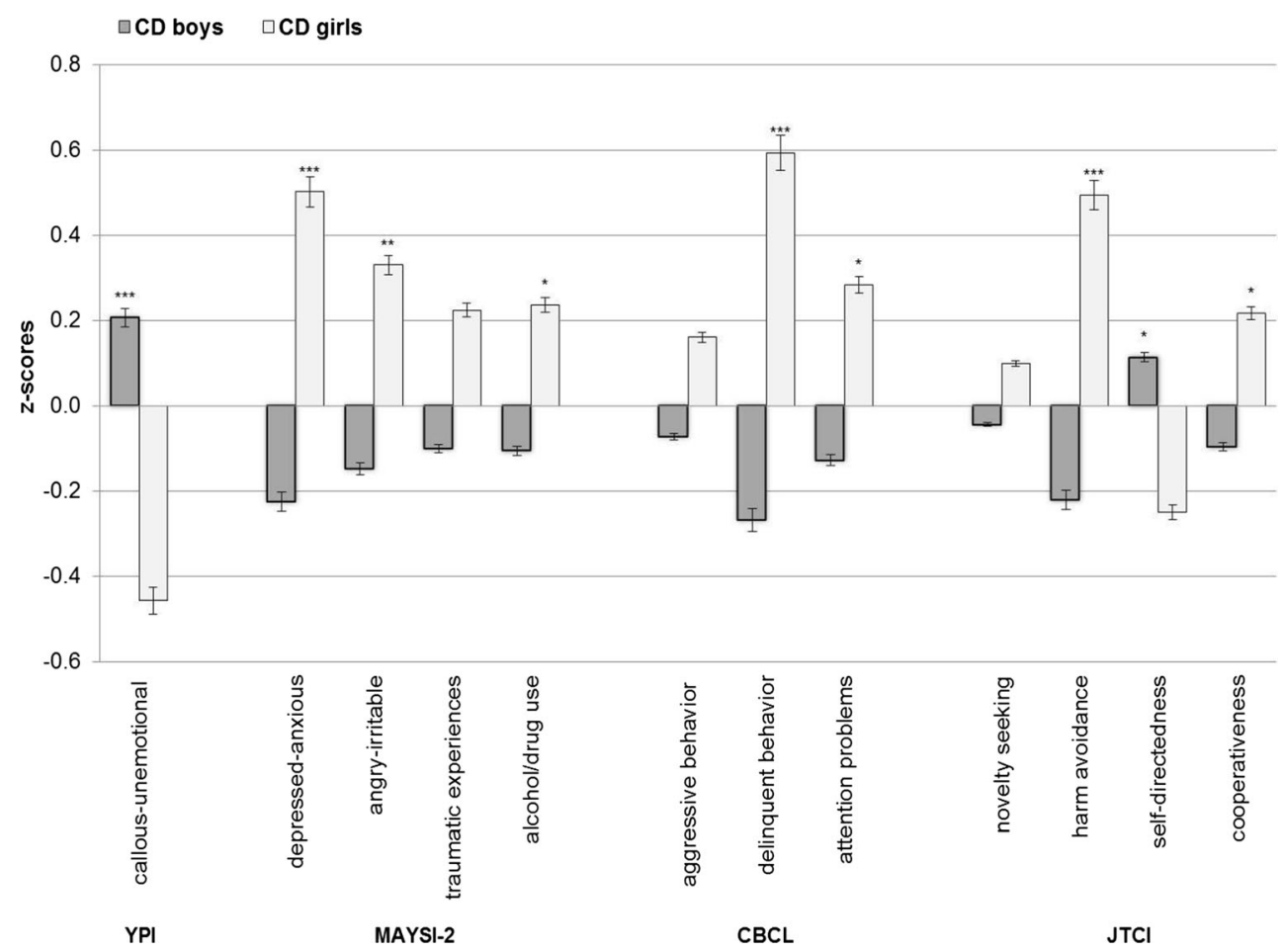


of $\mathrm{CU}$ traits using the $\mathrm{CU}$ dimension of a self-report questionnaire. It is recommended to use multiple sources of information to assess CU traits. Multi-method assessment is considered important because insufficient agreement between different sources of information has been reported (Fink et al. 2012). Nonetheless, Fink et al. (2012) showed that selfreport is more reliable than nonself-report for related constructs. It also needs to be considered that although the $\mathrm{CD}$ variant with moderate $\mathrm{CU}$ traits and anxiety symptoms scored significantly higher in the YPI CU dimension than the CD only variant and the Swiss norm sample, the mean score was not more than $1 \mathrm{SD}$ above the mean of the norm sample. Second, we used the DA subscale of the MAYSI-2 to assess anxiety symptoms. The MAYSI-2 is a screening instrument developed to identify youths with mental health needs. A high score on the scale does not necessarily indicate that anxiety symptoms can be interpreted as pathological trait anxiety. In our study, a high score on the MAYSI-2 DA scale merely indicated that adolescents exhibited symptoms of anxiety and/ or depression at the time of testing. Higher scores might have been caused by long-standing depression or anxiety problems as was assumed in our study, but similar elevations might also be seen as a reaction to an acute life stressor, for example having been arrested or placed in an institution. To confirm and validate the results of the present study, broader and more sophisticated measures of anxiety should be applied. This seems especially relevant since we used the MAYSI-2 DA scale as a clustering variable. Third, several additional aspects concerning the study population should be taken into account. Generalization of the present results to other psychiatric populations is questionable because adolescents living in childwelfare and juvenile-justice institutions are characterized by a unique socio-demographic background often with reduced access to, and use of mental health care (for a review see Fazel et al. 2008). Further, a high prevalence of comorbid mental health problems in antisocial adolescents in juvenile detention centers has previously been indicated (Cauffman 2004). It is also important to note that institutions differed in terms of psychological treatment and educational consulting offered. Moreover, adolescents were not always assessed directly after entering the institution. Thus, time points of assessment differed between adolescents. Nonetheless, we believe that the effects of these confounds are only of minor concern for the interpretation of our results, because only adolescents who reached thresholds for a DSM IV CD diagnosis at the time of testing were included in the study. We also did not control for a possible selection bias using clinical diagnosis, but used CBCL profiles to compare non-participating adolescents with those adolescents that were involved in the study. Despite our effort to investigate equally large groups of CD girls and boys, the proportion of girls in the present sample was smaller. Fourth, more than half of the adolescents included in the study had one or more comorbid disorder. Although overall there were no differences in the presence or the type of the comorbid disorders between identified variants - with the expected exception of anxiety disorders - this should be taken into account when interpreting our findings. Waschbusch (2002) emphasized that the co-occurrence of CD and ADHD symptoms leads to more severe conduct problems than $\mathrm{CD}$ or ADHD symptoms alone. We therefore included attention problems as a covariate in comparisons between variants, if attention problems were related to a measure of interest. Results remained unchanged and thus we conclude that in the present study cluster differences were not substantially driven by comorbid attention problems. The developmental context also needs to be considered when interpreting differences between subgroups with disruptive behavior results (Waschbusch 2002; Connor et al. 2007). It is possible that identified variants differed in the age of onset of their conduct problems. Because diagnostic interviews were not conducted with the parents, we were unfortunately not able to distinguish between childhood and adolescent onset of CD. Fifth, the data of the present study are cross-sectional and therefore, we cannot draw any conclusions on the temporal stability of identified variants throughout adolescents. Bearing these limitations in mind, we interpret our results as follows.

In line with our hypothesis, we identified two variants of $\mathrm{CD}$ patients with $\mathrm{CU}$ traits and altering levels of anxiety symptoms, and a third variant that was characterized by conduct problems only. CU traits refer to a set of characteristics similar to the affective features of adult psychopathy and represent a downward extension of the concept for children and adolescents (Frick and White 2008; Hart and Hare 1996). The two CD variants with CU traits identified in the present study elicit psychopathologies similar to the primary and secondary variants of psychopathy introduced by Karpman (1941; 1948). The CD only variant was numerically the largest cluster with the least severe psychopathologies. It has previously been reported that $\mathrm{CU}$ traits are negatively correlated with anxiety and neuroticism (Frick and White 2008). As an important finding, our data show that the presence of $\mathrm{CU}$ traits does not necessarily indicate the absence of anxiety symptoms in $\mathrm{CD}$ patients and may even suggest that the combination of anxiety and CU traits is associated with the most severe psychopathologies in CD. Interestingly, it has also been reported that the negative correlation of $\mathrm{CU}$ traits and anxiety symptoms is found only after controlling for conduct problems (Frick et al. 1999; Lynam et al. 2005). One of the strengths of the present study is that we diagnosed adolescents according to the DSM-IV, rather than using a dimensional approach to assess psychopathology. This method maximizes the relevance of our investigation to clinicians who generally work within a diagnostic framework. Moreover, the specifier for limited prosocial emotions that was included in the DSM-5 diagnostic criteria for CD designates $\mathrm{CD}$ patients that are characterized by a significant lack of 
remorse or guilt, show a callous lack of empathy, are unconcerned about their performance, and elicit shallow or deficient affect. Of notice, the YPI CU dimension comprises items to assess callousness, unemotionality, and remorselessness and thus captures a large proportion of the indicators of the DSM- 5 specifier for limited prosocial emotions in CD patients. Although no items to assess unconcern about performance in school or at work are included, the two variants with CU traits may represent groups of $\mathrm{CD}$ patients that would qualify for the specifier, with differences in the severity of the specifier, and differences in the presence of comorbid anxiety symptoms. Clearly, the validity of the YPI CU dimension to assess the characteristics of the $\mathrm{CD}$ specifier for limited prosocial emotions needs further evaluation and should be regarded as a first tentative approach towards an assessment of the specifier for scientific purposes.

Our second aim was to validate identified variants with respect to behavioral characteristics, psychopathology, and measures of personality development. The $\mathrm{CD}$ variant with moderate CU traits and prominent anxiety symptoms exhibited the most severe externalizing behavior and anger symptomatology in our study. This finding is somewhat contradictory to a number of studies indicating that particularly the group of adolescents with the most marked CU traits shows the most severe and stable pattern of aggressive behavior (Frick and Nigg 2012; Moffitt et al. 2008; Rowe et al. 2010; Viding et al. 2012). Nonetheless, the present findings are in line with the results of a study by Humayun et al. (2014), and provide further evidence for the assumption that it is the combination of $\mathrm{CU}$ traits and anxiety that is associated with the most severe aggressive and antisocial behavior, rather than $\mathrm{CU}$ traits alone. In addition, our results showed that the temperament dimension novelty seeking was more pronounced in both variants with $\mathrm{CU}$ traits than in the $\mathrm{CD}$ only variant. Further, a higher frequency and pervasiveness of alcohol and drug use was present in both CD variants with elevated CU traits, but not in the CD only variant. Frick et al. (1999) proposed that anxiety in antisocial individuals might result from higher rates of stressful life events following a tendency for risk taking behavior. In line with others (Poythress et al. 2010), the CD variant with moderate CU traits and anxiety symptoms in the present study did report traumatizing life events in the caution range. Hence, for the $\mathrm{CD}$ variant with $\mathrm{CU}$ traits and anxiety symptoms, the presence of anxiety symptoms might represent a consequence of the risk taking behavior. One could speculate that for the $\mathrm{CD}$ variant with severe $\mathrm{CU}$ traits without symptoms of anxiety, risk taking and antisocial behavior have led to positive outcomes (e.g. enhanced peer status, monetary gain) and consequently have reinforced the development and manifestation of CU traits. Elsewhere it has been discussed that $\mathrm{CU}$ traits emerge during childhood in reaction to a disadvantageous social environment (Kimonis et al. 2013). Thus, for the CD variant with CU traits and anxiety symptoms, the development of CU traits can also be interpreted as an adaptive mechanism to protect the individual from possible emotional or physical harm. However, developmental pathways of CU traits are still under debate. Other studies have emphasized heritabiltity and the interaction of reinforcement learning with genetic factors during socialization (for a review see Frick et al. 2014). Future longitudinal studies are requested to better understand the developmental interrelation of conduct problems, anxiety, temperament, and CU traits. We also found other differences in personality development between $\mathrm{CD}$ variants. The $\mathrm{CD}$ variant with moderate $\mathrm{CU}$ traits and anxiety symptoms scored higher in the harm avoidance dimension. This is in line with a study reporting higher harm avoidance in subjects with disruptive behavior disorders and comorbid internalizing problems (Rettew et al. 2004). Thus, CD patients with moderate $\mathrm{CU}$ traits and marked anxiety symptoms were characterized by a specific combination of behavioral activation and inhibition that has been associated with higher levels of neuroticism (Goth and Schmeck 2009). The character dimension cooperativeness represents the concept of how well an individual gets along with the needs and qualities of others, and self-directedness describes how well a person gets along with his or her own needs and qualities. $\mathrm{CD}$ patients with severe $\mathrm{CU}$ traits exhibited the lowest scores on the character dimension cooperativeness and lower scores on the self-directedness dimension than the $\mathrm{CD}$ only variant. The clinical significance of this pattern has been described as a dysfunctional, self-centered personality, and lower scores on both these dimensions are interpreted as a sign of immature character development that has been associated with personality disorders in adults (Svrakic et al. 2002). Adding valuable information to symptom-oriented characterization in $\mathrm{CD}$, the diagnostic potential of the assessment of temperament and character according to the personality concept of Cloninger using the JTCI was supported by the present results.

Our third aim was to address gender-specific questions related to the $\mathrm{CD}$ variants. With the inclusion of a large proportion of girls with $\mathrm{CD}$, our study makes an important contribution to the existing literature. Because genderassociated differences and gender-specific phenotypes of $\mathrm{CD}$ are still under debate, we aimed to compare CD girls and boys in the present sample. Our results indicated that CD girls, irrespective of cluster affiliation, had more severe behavioral problems, higher levels of anxiety, and lower scores of CU traits than $\mathrm{CD}$ boys. Girls were over-represented in the $\mathrm{CD}$ variant with moderate $\mathrm{CU}$ traits and anxiety symptoms, while there were more boys in the $\mathrm{CD}$ variant with severe $\mathrm{CU}$ traits. This result is in line with epidemiological research indicating 
that girls with CU traits do not necessarily show lower levels of anxiety (Essau et al. 2006), and that in girls anxiety symptoms are associated with more severe violent behavior (Wasserman et al. 2005). It has been outlined that CD girls with $\mathrm{CU}$ traits show more severe aggressive and antisocial behavior and more comorbid substance abuse compared to CD boys (Disney et al. 1999; Stadler et al. 2013). We also found the most severe disruptive behavior symptoms and highest levels of substance abuse in the $\mathrm{CD}$ variant with moderate CU traits and anxiety symptoms in this study. Although only one third of our study population was female, girls made up more than half of the adolescents in this cluster, while in the $\mathrm{CD}$ variant with severe $\mathrm{CU}$ traits most adolescents were boys. Overall, our results do not point towards the existence of a gender-specific subtype, but support the assumption of a CD gender paradox (Wasserman et al. 2005): Girls are less often affected by $C D$, but in case of a CD diagnosis, the severity of behavioral problems and rates of comorbid symptoms are higher, and therefore, developmental prognosis is less positive than in $\mathrm{CD}$ boys.

\section{Practical Implications and Future Directions}

Our results support previously formulated implications that specific treatment approaches are needed for $C D$ variants. For CD patients with comorbid anxiety problems, evidence-based cognitive behavioral treatments (Grasmann and Stadler 2011; Silverman et al. 2008) may be most effective. Interventions for $\mathrm{CD}$ patients with severe $\mathrm{CU}$ traits should focus on adequate emotional and empathic responding. It has been reported that instructions to focus on the eye region reduce deficits in the perception of other people's distress in children with CU traits (Dadds et al. 2006). Recent research has also indicated that the processing of distressing emotional stimulation seems to affect cognitive control in variants of $\mathrm{CD}$ patients differently (Euler et al. 2014) and should be considered in clinical practice. Despite these important implications, treatment of adolescents with $\mathrm{CU}$ traits is often difficult, because motivation and insight for the necessity of treatment are absent. Others have argued that the treatment of comorbid problems in conduct disorder children might solve this issue (Connor et al. 2007). Given the higher rates of comorbid anxiety symptoms, trauma and substance abuse in the $\mathrm{CD}$ variant with $\mathrm{CU}$ traits and pronounced anxiety symptoms, focusing on these comorbidities might also enhance compliance in this variant, even in the presence of $\mathrm{CU}$ traits. We conclude that improved understanding of the $\mathrm{CD}$ symptomatology requires consideration of $\mathrm{CU}$ traits as well as the presence of anxiety symptoms. Future longitudinal studies need to investigate possible developmental pathways of identified variants and test additional constructs differentiating between $\mathrm{CD}$ variants.
Acknowledgments The authors thank the MAZ research team and the MAZ evaluation team for the efforts made during data collection.

Conflict of Interest The authors declare that they have no conflict of interest.

\section{References}

Achenbach, T. M. (1991). Manual of the child behaviour checklist 4/18 and 1991 profile. Burlington: University of Vermont Department of Psychiatry.

American Psychiatric Association. (2000). Diagnostic and statistical manual of mental disorders: DSM-IV-TR. New Dehli: Jaypee Brothers Medical Publishers.

American Psychiatric Association. (2013). Diagnostic and statistical manual of mental disorders (5th ed.). Arlington: American Psychiatric Publishing.

Andershed, H., Kerr, M., Stattin, H., \& Levander, S. (2002). Psychopathic Traits in Non Referred Youth: Initial Test of a new assessment tool. In E. Blaauw, \& L. Sheridaan (Eds.), Psychophaths Current International Perspectives (pp. 131-158). The Hague: Elsevier. Deutsche Version: Schmeck, Hinrichs \& Fegert (2005).

Angold, A., Costello, E. J., \& Erkanli, A. (1999). Comorbidity. Journal of Child Psychology and Psychiatry, 40(1), 57-87.

Buitelaar, J. K., Smeets, K. C., Herpers, P., Scheepers, F., Glennon, J., \& Rommelse, N. N. (2013). Conduct disorders. European Child and Adolescent Psychiatry, 22(Suppl 1), S49-S54. doi:10.1007/s00787012-0361-y.

Cauffman, E. (2004). A statewide screening of mental health symptoms among juvenile offenders in detention. Journal of the American Academy of Child and Adolescent Psychiatry, 43(4), 430-439. doi: 10.1097/00004583-200404000-00009.

Cauffman, E., Kimonis, E. R., Dmitrieva, J., \& Monahan, K. C. (2009). A multimethod assessment of juvenile psychopathy: Comparing the predictive utility of the PCL:YV, YPI, and NEO PRI. Psychological Assessment, 21(4), 528-542. doi:10.1037/A0017367.

Cloninger, C. R., Przybeck, T. R., \& Svrakic, D. M. (1991). The tridimensional personality questionnaire: U.S. normative data. Psychological Reports, 69(3 Pt 1), 1047-1057.

Cloninger, C. R., Svrakic, D. M., \& Przybeck, T. R. (1993). A psychobiological model of temperament and character. Archives of General Psychiatry, 50(12), 975-990.

Connor, D. F., Ford, J. D., Albert, D. B., \& Doerfler, L. A. (2007). Conduct disorder subtype and comorbidity. Annals of Clinical Psychiatry, 19(3), 161-168. doi:10.1080/10401230701465269.

Copeland, W., Landry, K., Stanger, C., \& Hudziak, J. J. (2004). Multiinformant assessment of temperament in children with externalizing behavior problems. Journal of Clinical Child and Adolescent Psychology, 33(3), 547-556. doi:10.1207/s15374424jccp3303 12.

Dadds, M. R., Perry, Y., Hawes, D. J., Merz, S., Riddell, A. C., Haines, D. J., et al. (2006). Attention to the eyes and fear-recognition deficits in child psychopathy. British Journal of Psychiatry, 189, 280-281. doi: 10.1192/bjp.bp.105.018150.

Delmo, C., Weiffenbach, O., Gabriel, M., Stadler, C., \& Poustka, F. (2005). Kiddie-Sads-Present and Lifetime Version (K-SADS-PL). 5. Auflage der deutschen Forschungsversion, erweitert um ICD10-Diagnostik, Juli 2000/Juli 2001 Frankfurt am Main: Klinik für Psychiatrie und Psychothe-rapie des Kindes- und Jugendalters.

Disney, E. R., Elkins, I. J., McGue, M., \& Iacono, W. J. (1999). Effects of ADHD, conduct disorder, and gender on substance use and abuse in adolescence. American Journal of Psychiatry, 156(10), 1515-1521.

Dolan, M. C., \& Rennie, C. E. (2007). The relationship between psychopathic traits measured by the youth psychopathic trait inventory and 
psychopathology in a UK sample of conduct disordered boys. Journal of Adolescence, 30(4), 601-611. doi:10.1016/j. adolescence.2006.07.002.

Essau, C. A., Sasagawa, S., \& Frick, P. J. (2006). Callous-unemotional traits in a community sample of adolescents. Assessment, 13(4), 454-469. doi:10.1177/1073191106287354.

Euler, F., Sterzer, P., \& Stadler, C. (2014). Cognitive control under distressing emotional stimulation in adolescents with conduct disorder. Aggressive Behavior, 40(2), 109-119. doi:10.1002/ ab. 21508 .

Fanti, K. A., Demetriou, C. A., \& Kimonis, E. R. (2013). Variants of callous-unemotional conduct problems in a community sample of adolescents. Journal of Youth and Adolescence, 42(7), 964-979. doi:10.1007/s10964-013-9958-9.

Fazel, S., Doll, H., \& Langstrom, N. (2008). Mental disorders among adolescents in juvenile detention and correctional facilities: a systematic review and metaregression analysis of 25 surveys. Journal of the American Academy of Child and Adolescent Psychiatry, 47(9), 1010-1019. doi:10.1097/CHI.ObO13e31817eecf3.

Fink, B. C., Tant, A. S., Tremba, K., \& Kiehl, K. A. (2012). Assessment of psychopathic traits in an incarcerated adolescent sample: a methodological comparison. Journal of Abnormal Child Psychology, 40(6), 971-986. doi:10.1007/s10802-012-9614-y.

Frick, P. J., \& Ellis, M. (1999). Callous-unemotional traits and subtypes of conduct disorder. Clinical Child and Family Psychology Review, 2(3), 149-168.

Frick, P. J., \& Nigg, J. T. (2012). Current issues in the diagnosis of attention deficit hyperactivity disorder, oppositional defiant disorder, and conduct disorder. Annual Review of Clinical Psychology, 8(8), 77-107. doi:10.1146/annurev-clinpsy-032511-143150.

Frick, P. J., \& White, S. F. (2008). Research review: The importance of callous-unemotional traits for developmental models of aggressive and antisocial behavior. Journal of Child Psychology and Psychiatry, 49(4), 359-375. doi:10.1111/j.1469-7610.2007.01862.x.

Frick, P. J., Lilienfeld, S. O., Ellis, M., Loney, B., \& Silverthorn, P. (1999). The association between anxiety and psychopathy dimensions in children. Journal of Abnormal Child Psychology, 27(5), 383-392. doi:10.1023/A:1021928018403.

Frick, P. J., Ray, J. V., Thornton, L. C., \& Kahn, R. E. (2014). Annual research review: A developmental psychopathology approach to understanding callous-unemotional traits in children and adolescents with serious conduct problems. Journal of Child Psychology and Psychiatry, 55(6), 532-548. doi:10.1111/jcpp.12152.

Goth, K., \& Schmeck, K. (2009). Das junior temperament und charakter inventar. Göttingen: Hogrefe.

Grasmann, D., \& Stadler, C. (2011). VIA-an intensive therapeutic treatment program for conduct disorders. Zeitschrift für Kinder- und Jugendpsychiatrie und Psychotherapie, 39(1), 23-30. doi:10.1024/ 1422-4917/a000080. quiz 30-21.

Grisso, T., \& Barnum, R. (2006). Massachusetts youth screening instrument-version 2 (MAYSI-2): User's manual and technical report. Sarasota: Professional Recource Press.

Grisso, T., Fusco, S., Paiva-Salisbury, M., Perrauot, R., Williams, V., \& Barnum, R. (2012). The Massachusetts youth screening instrumentversion 2 (MAYSI-2): comprehensive research review. Worcester: University of MassachusettsMedical School. www.nysap.us.

Hart, S. D., \& Hare, R. D. (1996). Psychopathy and antisocial personality disorder. Current Opinion in Psychiatry, 9(2), 129-132. doi:10. 1097/00001504-199603000-00007.

Hodgins, S., de Brito, S., Simonoff, E., Vloet, T., \& Viding, E. (2009). Getting the phenotypes right: an essential ingredient for understanding aetiological mechanisms underlying persistent violence and developing effective treatments. Frontiers in Behavioral Neuroscience, 3, 44. doi:10.3389/neuro.08.044.2009.

Humayun, S., Kahn, R. E., Frick, P. J., \& Viding, E. (2014). Callousunemotional traits and anxiety in a community sample of 7-year- olds. Journal of Clinical Child and Adolescent Psychology, 43(1), 36-42. doi:10.1080/15374416.2013.814539.

Kahn, R. E., Frick, P. J., Youngstrom, E. A., Youngstrom, J. K., Feeny, N. C., \& Findling, R. L. (2013). Distinguishing primary and secondary variants of callous-unemotional traits among adolescents in a clinicreferred sample. Psychological Assessment, 25(3), 966-978. doi:10. 1037/A0032880.

Karpman, B. (1941). On the need of separating psychopathy into two distinct clinical types: The symptomatic and the idiopathic. Journal of Criminal Psychopathology, 3, 112-137.

Karpman, B. (1948). The myth of the psychopathic personality. American Journal of Psychiatry, 104(9), 523-534.

Keenan, K., Loeber, R., \& Green, S. (1999). Conduct disorder in girls: A review of the literature. Clinical Child and Family Psychology Review, 2(1), 3-19.

Keenan, K., Hipwell, A., Chung, T., Stepp, S., Stouthamer-Loeber, M., Loeber, R., et al. (2010). The Pittsburgh girls study: Overview and initial findings. Journal of Clinical Child and Adolescent Psychology, 39(4), 506-521. doi:10.1080/15374416.2010.486320.

Kimonis, E. R., Skeem, J. L., Cauffman, E., \& Dmitrieva, J. (2011). Are secondary variants of juvenile psychopathy more reactively violent and less psychosocially mature than primary variants? Law and Human Behavior, 35(5), 381-391. doi:10.1007/s10979-010-9243-3.

Kimonis, E. R., Frick, P. J., Cauffman, E., Goldweber, A., \& Skeem, J. (2012a). Primary and secondary variants of juvenile psychopathy differ in emotional processing. Development and Psychopathology, 24(3), 1091-1103. doi:10.1017/S0954579412000557.

Kimonis, E. R., Tatar, J. R., 2nd, \& Cauffman, E. (2012b). Substancerelated disorders among juvenile offenders: what role do psychopathic traits play? Psychology of Addictive Behaviors, 26(2), 212225. doi:10.1037/a0028047.

Kimonis, E. R., Fanti, K. A., Isoma, Z., \& Donoghue, K. (2013). Maltreatment profiles among incarcerated boys with callousunemotional traits. Child Maltreatment, 18(2), 108-121. doi:10. 1177/1077559513483002.

Lee, Z., Salekin, R. T., \& Iselin, A. M. R. (2010). Psychopathic traits in youth: Is there evidence for primary and secondary subtypes? Journal of Abnormal Child Psychology, 38(3), 381-393. doi:10. 1007/s10802-009-9372-7.

Lehto-Salo, P., Narhi, V., Ahonen, T., \& Marttunen, M. (2009). Psychiatric comorbidity more common among adolescent females with CD/ODD than among males. Nordic Journal of Psychiatry, 63(4), 308-315. doi:10.1080/08039480902730615.

Lynam, D. R., Caspi, A., Moffitt, T. E., Raine, A., Loeber, R., \& Stouthamer-Loeber, M. (2005). Adolescent psychopathy and the big five: results from two samples. Journal of Abnormal Child Psychology, 33(4), 431-443.

Moffitt, T. E., Arseneault, L., Jaffee, S. R., Kim-Cohen, J., Koenen, K. C., Odgers, C. L., et al. (2008). Research review: DSM-V conduct disorder: research needs for an evidence base. Journal of Child Psychology and Psychiatry, 49(1), 3-33. doi:10.1111/j.1469-7610. 2007.01823.x.

Olsson, M. (2009). DSM diagnosis of conduct disorder (CD)-a review. Nordic Journal of Psychiatry, 63(2), 102-112. doi:10.1080/ 08039480802626939.

Pajer, K., Stein, S., Tritt, K., Chang, C. N., Wang, W., \& Gardner, W. (2008). Conduct disorder in girls: neighborhoods, family characteristics, and parenting behaviors. Child and Adolescent Psychiatry and Mental Health, 2(1), 28. doi:10.1186/1753-2000-2-28.

Pardini, D. A., Lochman, J. E., \& Powell, N. (2007). The development of callous-unemotional traits and antisocial behavior in children: are there shared and/or unique predictors? Journal of Clinical Child and Adolescent Psychology, 36(3), 319-333. doi:10.1080/ 15374410701444215.

Pardini, D., Stepp, S., Hipwell, A., Stouthamer-Loeber, M., \& Loeber, R. (2012). The clinical utility of the proposed DSM-5 callous- 
unemotional subtype of conduct disorder in young girls. Journal of the American Academy of Child and Adolescent Psychiatry, 51(1), 62-73. doi:10.1016/j.jaac.2011.10.005.

Polier, G. G., Vloet, T. D., Herpertz-Dahlmann, B., Laurens, K. R., \& Hodgins, S. (2012). Comorbidity of conduct disorder symptoms and internalising problems in children: Investigating a community and a clinical sample. European Child and Adolescent Psychiatry, 21(1), 31-38. doi:10.1007/s00787011-0229-6.

Poythress, N. G., Edens, J. F., Skeem, J. L., Lilienfeld, S. O., Douglas, K. S., Frick, P. J., et al. (2010). Identifying subtypes among offenders with antisocial personality disorder: A cluster-analytic study. Journal of Abnormal Psychology, 119(2), 389-400. doi:10.1037/ a0018611.

Raven, J., Raven, J. C., \& Court, J. H. (2003). Manual for Raven's progressive matrices and vocabulary scales. San Antonio: Harcourt Assessment.

Rettew, D. C., Copeland, W., Stanger, C., \& Hudziak, J. J. (2004). Associations between temperament and DSM-IV externalizing disorders in children and adolescents. Journal of Developmental and Behavioral Pediatrics, 25(6), 383-391. doi:10.1097/00004703200412000-00001.

Rowe, R., Maughan, B., Moran, P., Ford, T., Briskman, J., \& Goodman, R. (2010). The role of callous and unemotional traits in the diagnosis of conduct disorder. Journal of Child Psychology and Psychiatry, 51(6), 688-695. doi:10.1111/j. 1469-7610.2009.02199.x.

Russo, M. F., \& Beidel, D. C. (1994). Comorbidity of childhood anxiety and externalizing disorders - prevalence, associated characteristics, and validation issues. Clinical Psychology Review, 14(3), 199-221.

Schmeck, K., \& Poustka, F. (2001). Temperament and disruptive behavior disorders. Psychopathology, 34(3), 159-163.

Schmeck, K., Goth, K., Cloninger, C. R., \& Poustka, F. (2001). Reliability and validity of the junior temperament and character inventory. International Journal of Methods in Psychiatric Research, 10, 172-182.

Schmid, M., Kölch, M., Fegert, J. M., Schmeck, K., \& MAZ.-Team (2013). Abschlussbericht Modellversuch Abklärung und Zielerreichung in stationären Massnahmen. Zugriff unter http:// www.ejpd.admin.ch/ejpd/de/home/themen/sicherheit/ref_straf und_massnahmevollzug/ref_modellversuche/ref_ evaluationsberichte.html.

Silverman, W. K., Pina, A. A., \& Viswesvaran, C. (2008). Evidencebased psychosocial treatments for phobic and anxiety disorders in children and adolescents. Journal of Clinical Child and Adolescent Psychology, 37(1), 105-130. doi:10.1080/15374410701817907.

Sourander, A., Jensen, P., Davies, M., Niemela, S., Elonheimo, H., Ristkari, T., et al. (2007). Who is at greatest risk of adverse longterm outcomes? the Finnish from a Boy to a Man study. Journal of the American Academy of Child \& Adolescent Psychiatry, 46(9), 1148-1161. doi:10.1097/chi.0b013e31809861e9.

Stadler, C., Poustka, F., \& Sterzer, P. (2010). The heterogeneity of disruptive behavior disorders - implications for neurobiological research and treatment. Frontiers in Psychiatry, 1(21), 1-14. doi: 10.3389/fpsyt.2010.00021.

Stadler, C., Euler, F., \& Schwenck, C. (2013). Girls with conduct disorder: Are there gender-specific effects? Kindheit und Entwicklung, 22(3), 127-138. doi:10.1026/0942-5403/A000110.

Svrakic, D. M., Draganic, S., Hill, K., Bayon, C., Przybeck, T. R., \& Cloninger, C. R. (2002). Temperament, character, and personality disorders: Etiologic, diagnostic, treatment issues. Acta Psychiatrica Scandinavica, 106(3), 189-195.

Viding, E., Fontaine, N. M. G., \& McCrory, E. J. (2012). Antisocial behaviour in children with and without callous-unemotional traits. Journal of the Royal Society of Medicine, 105(5), 195-200. doi:10. 1258/jrsm.2011.110223.

Vloet, T. D., \& Herpertz-Dahlmann, B. (2011). The meaning of anxiety in the phenotyping of children and adolescents with conduct disorder a path toward more consistent neurobiological findings? Zeitschrift für Kinder- und Jugenpsychiatrie und Psychotherapie, 39(1), 4757. doi:10.1024/1422-4917/a000083.

Waschbusch, D. A. (2002). A meta-analytic examination of comorbid hyperactive-impulsive-attention problems and conduct problems. Psychological Bulletin, 128(1), 118-150. doi:10.1037/0033-2909. 128.1.118.

Wasserman, G. A., McReynolds, L. S., Ko, S. J., Katz, L. M., \& Carpenter, J. R. (2005). Gender differences in psychiatric disorders at juvenile probation intake. American Journal of Public Health, 95(1), 131-137. doi:10.2105/Ajph.2003.024737.

Weiss, R. H. (2006). Grundintelligenztest Skala 2-Revision (CFT 20R). Göttingen: Hogrefe. 